\title{
A VUELTAS CON LA CULTURA: IMÁGENES DEL ALUMNADO INMIGRANTE EN LAS AULAS DE ENLACE DE LA COMUNIDAD DE MADRID (ESPAÑA)
}

\author{
A RETURN TO THE CULTURE: IMAGES OF IMMIGRANT STUDENTS \\ IN LINKAGE CLASSROOMS OF MADRID (SPAIN)
}

\author{
Pilar Cucalón Tirado*
}

\begin{abstract}
El presente artículo es fruto de un proceso de investigación etnográfica desarrollado a lo largo de tres cursos escolares (20082011) en las Aulas de Enlace, un programa escolar dirigido exclusivamente al alumnado inmigrante/extranjero recién llegado a la Comunidad de Madrid (España) para facilitar su incorporación en el sistema educativo. La finalidad del texto es dar cuenta de las imágenes que los docentes proyectan sobre dichos estudiantes, las diferencias culturales que les atribuyen y las consecuencias de estas percepciones, tanto de cara a los chicos y chicas como a la propia escuela, especialmente en relación con las expectativas y las trayectorias escolares.
\end{abstract}

Palabras claves: Diferencias culturales, sistema educativo, estudiantes inmigrantes, trayectorias escolares y etnografía.

This article is based upon and ethnographic research carried out from 2008 until 2011 in Aulas de Enlace [literally, Linking Classrooms]. Aulas de Enlace are a program of the Community of Madrid (Spain) aimed exclusively at migrant students recently arrived to facilitate their transition into the school system. This paper analyzes teachers' images of students, cultural differences attributed, and consequences of these perceptions, not only in the lives of the students but also in the school itself, regarding expectations toward students and their school trajectories.

Key words: Cultural differences, school system, migrant students, school trajectories and ethnography.

\section{Introducción}

En este artículo me propongo analizar los discursos de los docentes en torno a la categoría cultura como un aspecto que les permite explicar la trayectoria de los estudiantes inmigrantes/extranjeros en la Comunidad de Madrid (España). La finalidad última es mostrar, por un lado, sus imágenes respecto de dicho concepto y, por otro, y fundamentalmente, explicar que, a pesar de una cada vez mayor aceptación por las diferencias dentro de la escuela, sigue imperando una mirada centrada en origen del sujeto que determina las percepciones de los profesores y tiene consecuencias en los procesos de enseñanza/aprendizaje. Esto resulta altamente problemático puesto que la adscripción cultural se utiliza como argumento para justificar un déficit en los estudiantes, bien debido a la lengua, a los sistemas educativos de los países de origen o a otras causas que identifican con la cultura. A su vez, esta percepción deficitaria justifica una incorporación desigualitaria en el sistema educativo, respecto de sus pares nacidos en España, y finalmente en el mercado de trabajo

La llegada más numerosa de los estudiantes inmigrantes/extranjeros al sistema educativo madrileño tuvo lugar a principios de la década de $\operatorname{los} 2000^{1} \mathrm{y}$ fue acompañada por el discurso de las diferencias culturales (García Castaño et al. 1999). Sin embargo, las dificultades que se consideraban derivadas de esta presencia, no solo eran fruto de que hubiera un alumnado con el que antes no se había trabajado, sino que ponían en evidencia cuestiones no resueltas tampoco con el alumnado autóctono, como es el caso de una intervención compensadora ante los niños y jóvenes a los que se considera diferentes por razones étnicas o de clase social.

Ante la situación esbozada me planteé la necesidad de desarrollar una investigación etnográfica en el seno de las Aulas de Enlace, debido a que me permitía examinar el día a día de un programa escolar dirigido exclusivamente al alumnado inmigrante/extranjero recién llegado a la Comunidad de Madrid, y cuyas finalidades principales, expresadas

\footnotetext{
* Universidad Nacional de Educación a Distancia (UNED), Madrid. Correo electrónico: pilarcucalon82@ gmail.com
} 
por las normativas y directrices del programa, son: a) la incorporación al sistema educativo y sociedad en las mejores condiciones y en el menor tiempo posible; b) la adquisición del castellano en el caso que se desconozca; c) trabajo sobre el desfase curricular en el caso de que lo haya; d) el fomento de la identidad personal y cultural de los jóvenes. Las Aulas de Enlace se caracterizan por estar separadas de las aulas ordinarias, por contar con un máximo de doce estudiantes y por establecer que el tiempo de permanencia no puede superar los nueve meses. Mientras discurre la escolarización en el Aula de Enlace los estudiantes van integrándose de manera paulatina en sus grupos ordinarios, que son a su vez de los que formarán parte cuando terminen el programa $^{2}$.

Llevé a cabo mi trabajo de campo durante tres años (de 2008 a 2011) en dos Aulas de Enlace de Educación Secundaria Obligatoria, que escolarizaban a estudiantes inmigrantes/extranjeros entre los 12 y los 16 años de edad. Cada una se encontraba ubicada en un centro educativo distinto: uno de titularidad pública en una pequeña ciudad del área metropolitana de Madrid capital y otro privadoconcertado $^{3}$ situado en un barrio de la ciudad de Madrid. En este artículo utilizaré el nombre de IES Cantueña y Colegio Mica (ambos ficticios, así como los de las personas entrevistadas ${ }^{4}$ ) para referirme respectivamente a cada una de estas escuelas.

Las características y finalidades de las Aulas de Enlace las convierten en un ámbito idóneo para analizar los discursos de los docentes en cuanto a la diversidad cultural, que es el tema en el que se centra este artículo.

\section{Diferencias culturales: entre el respeto, el esencialismo y la necesidad de corrección}

Durante mi trabajo de campo en el curso 200809 asistí a la celebración de la fiesta intercultural en el IES Cantueña. A continuación, voy a incluir algunas de las notas que tomé durante esa mañana.

...aparece en la pantalla un mapa de Rumania, que explica su extensión, la capital y la religión principal. A continuación aparecen los nombres y fotografías de personajes históricos en el país. Finaliza con una foto indicando que los retratados son los niños de nacionalidad rumana que pertenecen al instituto. Me fijo en que uno de los chicos de la foto lleva una camiseta de la selección española. Tras esta presentación, sube al escenario un estudiante que habla sobre Ecuador, apoyándose con una exposición en Power point. Pone fotos de personas vestidas con coloridas faldas, la bandera de Ecuador, una breve explicación de la historia contemporánea del país, los lugares en los que se puede hacer turismo, las principales ciudades y, además, un mapa con las nacionalidades indígenas del Ecuador. Después comienza la presentación sobre China, que ha elaborado la profesora del Aula de Enlace -Elena-. Aparecen fotografías de las estudiantes del programa en excursiones que han hecho por Madrid y también del centro escolar de una alumna, como permite adivinar uno de los títulos "Así son sus colegios". La exposición prosigue con diferentes apartados, uno de ellos pregunta ¿cómo los vemos? y ¿cómo son realmente? A lo que se contesta en otra diapositiva exponiendo que los alumnos chinos tienen muchas ganas de participar, de integrarse y son muy amables. En el mismo Power point hablan de su cultura, como "algo enigmático y a conocer". Para representar a España un grupo baila flamenco... (Observación en el IES Cantueña: salón de actos-fiesta de la interculturalidad. Extracto de mi diario de campo. Mayo de 2009).

A raíz de esta experiencia considero pertinente plantear las siguientes preguntas: ¿qué papel juegan los profesores en la producción de diferencias entre estudiantes según su procedencia?, ¿cómo se entiende la interculturalidad?, ¿cómo definen los profesores y alumnos las diferencias culturales? y ¿qué repercusiones ha tenido sobre el día a día de los centros educativos la entrada de chicos y chicas extranjeros?

En la fiesta "intercultural" algunas imágenes estereotipadas de los países de procedencia de los estudiantes extranjeros son construidas como emblemas de diferencia (Franzé, 2008). En este sentido, radicalizar la diferencia es una forma de racismo que se produce al concebir determinados rasgos como esencias que definen a sujetos individuales y colectivos, y además como particularidades que determinan otras características (Fassin, 2006). 
En este artículo, incidiré principalmente en las explicaciones culturalistas y su repercusión en el transitar de los jóvenes inmigrantes en los centros educativos. De tal modo que los comportamientos, actitudes, expectativas escolares y formas de agrupamiento con los pares son concebidas por el profesorado y alumnado como un todo que impregna a los sujetos y determina sus prácticas. Además, daré cuenta de los atributos que los agentes consideran propios de todas las personas de un mismo grupo étnico-nacional. Dichas explicaciones los esencializan, sin embargo no solo son utilizadas por el profesorado, sino también por algunos chicos y chicas entrevistados 5 .

En primer lugar, analizaré las imágenes de los docentes entrevistados respecto del alumnado inmigrante que habita las Aulas de Enlace y centros educativos y al peso que otorgan a las culturas de origen para explicar las trayectorias escolares. En segundo, me detendré en las representaciones respecto de los jóvenes de nacionalidad china, que es el grupo mayoritario en las clases investigadas. En tercer lugar, me voy a detener en cómo los profesores piensan que la cultura construye la feminidad en relación con el atuendo.

\section{Las imágenes de los docentes respecto del alumnado inmigrante}

La escuela intenta generar sus propias explicaciones de cara al desarrollo académico de sus estudiantes. La baja motivación escolar o la indisciplina son atribuidas a muchas razones, pero la entrada a los centros educativos de la población migrante ha favorecido el discurso sobre las diferencias culturales.

Los veo muy ricos, los aprecio enormemente, cuando sé lo que pueden estar pasando pues me preocupo, a lo mejor no están pasando tanto pero el hecho de estar fuera de su país y tenerse que arraigar en este me preocupa. Los veo muy concienciados por el estudio, los veo también muy dispersos porque son muy adolescentes. Los veo juguetones, creo que se han contagiado de cierto estilo de un alumnado nacional que es muy espontáneo, que grita mucho, le gusta escaquearse de las cosas, llegar tarde a las clases, que sus puntos de encuentro son los pasillos. Eso digamos que es el mimetismo con respecto a los nuestros. Pero yo cuando les miro a la cara y veo que quieren aprender y que se esfuerzan pues la verdad es que me emocionan. (Entrevista a Martina. Profesora de Aula de Enlace y referencia en el Colegio Mica. Junio 2009).

En este caso, Martina hace referencia a la influencia, al "contagio" que los chicos inmigrantes han vivido respecto de la falta de motivación en los estudios y otras particularidades. Al mismo tiempo que describe a los estudiantes "nacionales" va explicando también, por nacionalidades, cómo ve a los estudiantes del Aula de Enlace en función de dichos lugares de procedencia y establece diferencias entre grupos en relación con el aprendizaje y cómo se "integran".

El alumnado que tenemos es un porcentaje elevadísimo chino, pues han creado unos conflictos entre sí, que ellos se entienden y que los demás no lo entendemos. He intentado buscar estrategias del tipo de penalizar sus intervenciones en chino. Me parece que es abusar por mi parte, pero creo que hay que hacerlo, para que se den cuenta que si no aprenden tendrán que aprender en un aula y en otras horas, y que se incremente el número de horas y les quita ocio. Entonces, como una posibilidad para el curso que viene, pero bueno que se den cuenta que vienen a aprender hablar español y no a hablar en chino y que son los únicos momentos para aprender español, porque fuera de aquí yo les he preguntado, tú también eres consciente de que están integrados en grupos de chinos e incluso tienen que dedicar horas a algún trabajillo y que viven muy lejos, su núcleo de amigos no es del barrio, viven en otros barrios y fundamentalmente se relacionan con compañeros de su misma procedencia. Hay otro grupo, los chicos rumanos, yo creo que sí se integran bien, la chica brasileña también, está muy contenta en este colegio. Me agrada, porque los veo tímidos (Entrevista a Martina. Profesora de Aula de Enlace y referencia en el Colegio Mica. Junio 2009). 
Durante mi entrevista a Álvaro, también profesor del Colegio Mica, iba enumerando las particularidades que veía en cada estudiante según su grupo nacional. Consideraba que en el centro educativo no había llegado a producirse "interculturalidad", debido a que cada chico o chica se agrupaba en función de su origen. Algo que destacaba, sobre todo, en relación con los jóvenes de China. Respecto de los alumnos procedentes de Latinoamérica reconocía que no se sentían legitimados en las clases, porque los contenidos y formas de trabajar de sus anteriores centros educativos eran diferentes.

Hay alumnos, por ejemplo, los brasileños, sí suelen conectar muy bien en los grupos de referencia. Por lo menos, los que yo he experimentado, conectan muy bien. A los árabes les cuesta un poco más. También terminan conectando porque suelen tener un carácter, son culturalmente más extrovertidos. A los chinos les cuesta muchísimo. A otras nacionalidades latinoamericanas, yo creo que tienen bastante, sí, vamos, el nivel de la integración lo tienen muy bien. Aunque yo he visto también que se sienten un poco, no sé, si acomplejados en el tema del trabajo, porque vienen de formas de trabajar muy distintas y con contenidos curriculares muy distintos. Pero, vamos, como no tienen la barrera del idioma, de cara a la comunicación. Yo, por lo menos, lo que he experimentado, los chicos latinoamericanos si hay chicos latinoamericanos en la clase se produce ese enganche, ¿no?, y terminan yendo casi siempre con otros chicos latinoamericanos. Y luego, pues lo que hablábamos el otro día, llegas al recreo, los latinos, los chinos al baloncesto e interculturalidad no demasiada (Entrevista a Álvaro. Exprofesor de Aula de Enlace y docente de grupo referencia en el Colegio Mica. Junio 2009).

Cuando pregunté a Elena, profesora del Aula de Enlace, sobre las interacciones que los estudiantes mantenían con los compañeros del centro, me respondió:

Hay de todo, depende mucho de la nacionalidad de los alumnos. Hay alumnos que, por lo general, hay nacionalidades que por lo general son más abiertas y se relacionan sin ningún problema y a otras hay que ayudarles a que se integren y en otras nos resulta muy difícil. Son culturas bastante, no sé si decir, cerradas o poco abiertas y que les cuesta la interacción con los alumnos (Entrevista a Elena, profesora del Aula de Enlace en el IES Cantueña. Junio 2009).

Elena, tras estas palabras en las que da un peso fundamental a las nacionalidades para explicar las interacciones que los jóvenes establecen con otros compañeros y compañeras del instituto, prosiguió la entrevista explicando la figura del alumno mentor ${ }^{6}$, como una estrategia desarrollada en el centro que funcionaba "fenomenal" para ayudar a los estudiantes a incorporarse a las clases de referencia ${ }^{7}$. Indicó que cada persona hace un uso diferente de la colaboración que otro compañero o compañera le presta como alumno o alumna mentora. Señalaba que los deseos de escolarizarse en los grupos de referencia también dependían de cada chico o chica aunque el proceso fuera difícil, en sus palabras "es muy cómodo estar en el Aula de Enlace, pero bueno la vida es también un reto y hay que ayudarles, empujarles a lo que hay". También indicaba que algunos jóvenes van "encantados" y les "piden acelerar el proceso".

Al plantearle la cuestión de las resistencias que algunos y algunas jóvenes desarrollaban, o no, de cara a abandonar el Aula de Enlace y las razones que veía en dichas diferencias, me respondió:

Depende del carácter del alumno, la nacionalidad y luego del grado o nivel de conocimiento del idioma que se tenga, también. Los alumnos de Europa del Este se integran muy fácilmente, es gente abierta, por lo general, luego encontramos también alumnos tímidos, gente abierta y gente que no suele tener dificultades en el aprendizaje del idioma y suele integrarse bien. Los marroquíes no suelen tener ningún problema en lo que se refiere a la integración, a nivel social, son participativos, es gente muy activa que normalmente participa fuera del Aula de Enlace y fuera del centro en actividades de deporte, por ejemplo, que les hace también conocer a otras personas y esos suelen tener menos problemas y hay otras nacionalidades que 
quizá les cuesta un poquito más (Entrevista a Elena, profesora del Aula de Enlace en el IES Cantueña. Junio 2009).

Respecto de la inclusión de los estudiantes en las aulas de referencia, Elena sitúa las explicaciones en tres ámbitos: el carácter de cada persona, la nacionalidad y el grado de conocimiento del castellano. En relación con estos tres aspectos se centra en los alumnos de "Europa del Este" y "marroquíes" para exponer sus facilidades en la "integración", como consecuencia de su apertura y facilidad con el idioma y su participación en diferentes ámbitos, respectivamente. Sin embargo, ve que hay otras nacionalidades que tienen más dificultades en la mencionada "integración".

\section{El alumnado de China: la expresión máxima de la diferencia cultural}

Como ya he indicado, la mayor parte del alumnado de las Aulas de Enlace en las que he realizado el trabajo de campo, era de nacionalidad china. Los profesores les atribuyen una serie de características que definen como "culturales" y que, de algún modo, interfieren en el día a día de los estudiantes. De dichas particularidades me resultan significativas aquellas que señalan que se trata de personas que principalmente establecen contactos con las de su mismo grupo étnico-nacional. Es decir, que no se relacionan con el resto de compañeros y compañeras de los centros educativos. Los docentes consideran que el hecho de que los chicos y chicas de China no creen dichos lazos tiene repercusiones en su aprendizaje del castellano y, por ello, en su manera de desenvolverse en las clases de referencia ${ }^{8}$.

El chino pienso que con nueve meses que esté en el Aula de Enlace no es suficiente. Entre otras cosas porque otras nacionalidades se empapan, viven, se empapan de la cultura española desde el primer día, ven la televisión, van a la compra, juegan en el parque con gente española, entonces les es más fácil. Sin embargo, los chinos viven exclusivamente el español en el Aula de Enlace, fuera del Aula de Enlace ven la televisión china, se relacionan solamente con personas de su cultura. Por lo tanto, con el tiempo que pasan en el Aula de Enlace es muy difícil que en nueve meses estén preparados con un nivel de conocimiento del castellano como para poder tener una conversación normal, poder entender unas ciencias sociales (Entrevista a Elena. Profesora del Aula de Enlace en el IES Cantueña. Junio de 2009).

Al hilo de esta argumentación, otro profesor enfatizaba la misma idea:

Fidel: ... Les cuesta muchísimo en nuestro idioma, eh, al grupo de los niños chinos. La mayoría de ellos, los que yo he tenido, uff, les cuesta que hablen, que te digan algo. Entienden, pero se expresan muy poquito. Sabes qué pasa, es que este chico, lo que ha conseguido es, pues, dedicarse a las bromas que hacen los niños, hacer las mismas bromas, pero entender y comunicarse bien no y entonces decía una cosa y resultaba graciosa a los otros y la repetía. Entonces, eh, realmente no les ha contado muchas cosas, sino que era el bromista. Y lo han admitido como el bromista. Estaban esperando a que él dijera alguna historia, pero realmente yo creo que ese niño no se ha integrado bien. Se ha integrado mejor, aunque parezca que no, Khady que él. Este chico, pero es que son muy complicados de transmitir si están a gusto, si no están a gusto, no lo notas si un niño está a gusto o no en clase, de así, de un niño chino me refiero. No lo ves, a mí me cuesta muchísimo ver si están. He tenido en el otro primero 9 otra niña, que luego se marchó, era una niña encantadora, de nueves, trabajadora pero no conseguía saber si estaba a gusto en clase o no. Esa sensación de decir estoy cómoda era muy complicado. Es muy complicado. A mí me cuesta con los niños chinos ver si están a gusto o no están a gusto.

Pilar: $Y_{¿}$ con niños de otras nacionalidades?

Fidel: Se nota mejor si un chico está cómodo (va nombrando a los niños del grupo y sus nacionalidades). Son chicos que les notas que están más cómodos. Pero los chinos cuesta mucho. A mí, al menos, me cuesta mucho ver si son capaces de. Solo un niño del año pasado (dice el nombre del 
niño), que se lo llevaron a China y que el hombre llevaba muchos años en España, desde los seis años. Entonces, era capaz de decirte algo, de gastarte alguna broma. Estos niños están, les cuesta muchísimo, pero sobre todo estos chicos. En el resto de la gente no se nota tanto (Entrevista a Fidel. Profesor de aula de referencia en el IES Cantueña. Junio de 2009).

$\mathrm{Al}$ mismo tiempo ven su comportamiento en clase como ejemplar y con potencialidades para obtener unas buenas calificaciones en materias como matemáticas o inglés. En este sentido, Fidel recalcaba en la entrevista (que he incluido en la cita anterior) que había una estudiante de nacionalidad china en su clase, "encantadora, de nueves ${ }^{10}$, trabajadora". Elena describe a los alumnos chinos como "buenos" para sus docentes y utiliza adjetivos como "atentos, cordiales, trabajadores"; sin embargo, considera que hay un problema en su aprendizaje: la lentitud como consecuencia de la diferencia "grandísima" entre idiomas. A pesar de ello, cuando se refiere a los estudiantes del curso 2008-09 reconoce que han aprendido "bien", aunque vayan más lentos, pero considera que dicha lentitud tiene que ver con la "cultura". Una cultura que, como ya he indicado en párrafos precedentes, es considerada como determinante y lleva a sus miembros a que "se relacionen solamente con personas de su cultura", de tal modo que no "se empapan de la cultura española" $\mathrm{y}$, por ello, tienen problemas para desenvolverse en castellano.

Más de la mitad de los alumnos eran chinos. Los alumnos chinos son muy buenos, desde el punto de vista del profesor. Alumnos atentos, cordiales, trabajadores, por lo tanto muy bien, pero aprenden muy lento, porque la diferencia entre el idioma chino y el idioma castellano es grandísima. Empezando porque muchos ni siquiera saben la grafía. Entonces, este año se ha notado la diferencia entre el nivel que adquiere un polaco de un chino. Bueno, pues parece que han aprendido menos, porque van más lentos, pero no realmente el grupo de chinos que hemos tenido ha aprendido bien, pero es que claro la cultura es diferente (Entrevista a Elena. Profesora en el Aula de Enlace del IES Cantueña. Junio de 2009).
Respecto de la grafía a la que Elena hace mención, no podría afirmar que todos los estudiantes chinos escolarizados en el Aula de Enlace del IES Cantueña conocieran el castellano, pero la mayor parte de los chicos y chicas con las que coincidí había estudiado inglés en su sistema educativo, de tal modo que habían tenido un acercamiento al alfabeto latino.

Ante las explicaciones de Elena respecto de los comportamientos de los chicos y chicas de nacionalidad china ante el aprendizaje, también querría añadir que a lo largo de mi trabajo de campo, aunque muchos mostraran sus expectativas a la hora de seguir estudiando, sus posicionamientos ante la formación eran diferentes. Así había alumnos que sus profesores calificaban de comportamiento intachable y actitud hacia el estudio constante, pero también otros que se enfrentaban a sus maestros y obtenían calificaciones muy bajas en sus aulas de referencia e informes negativos dentro del Aula de Enlace.

Otros docentes también han señalado que las dificultades del alumnado de nacionalidad china estaban relacionadas con su cultura de procedencia, no solo con las similitudes o diferencias respecto del idioma o al sistema educativo de referencia.

...David me dice que con los chinos el problema no solo tiene que ver con el hecho de que su lectoescritura sea muy diferente, sino que tienen una forma distinta de entender las cosas, que tienen otra "cultura", que solo se relacionan con chinos y de esta forma no se fomenta el aprendizaje del castellano, que son cerrados sobre sí mismos. Además, piensa que su sistema escolar no tiene nada que ver con el de aquí y que cree que muchos trabajan muchas horas en sus casas, porque siempre tienen mucho sueño en la escuela... (Observación en el Colegio Mica. Conversación con David, profesor de Aula de Enlace. Extracto de mi diario de Campo. Abril de 2009).

Los alumnos y alumnas de nacionalidad china son vistos por sus profesores, desde una mirada que los generaliza como "muy buenos", debido a sus actitudes en clase y su nivel en determinadas materias como matemáticas e inglés. Sin embargo, las diferencias entre el chino y el castellano generan, según los docentes, que su aprendizaje se retrase. 
Diferencias que, por otro lado, consideran que se acentúan como consecuencia de su cultura de pertenencia, que les lleva a establecer únicamente contactos entre personas de la misma nacionalidad.

Al mismo tiempo, los jóvenes de dicha nacionalidad también explicaban las relaciones que tejían entre sí como resultado de las diferentes costumbres que asocian a su lugar de procedencia.

Dice Xiao que sus compañeros se portan bien con ella, que son amables pero no sale a la calle con chicos de España. Piensa que hay personas en España a las que no le gustan las que vienen de China. Ella solo sale con chicos chinos. Le pregunto por qué. Me contesta que por el idioma y por las costumbres. Le pregunto cuáles son esas costumbres diferentes. Ella dice que la manera de ligar, que es más rápida y se nota más (Observación en IES Cantueña. Extracto de mi diario de campo. Marzo 2011).

Es fundamental respecto de las relaciones que establecen entre compatriotas, a mi modo de ver, como me explicaba un estudiante del Colegio Mica, que muchas personas en China emigran desde las mismas áreas, de tal modo que algunos jóvenes no rompen con las amistades al migrar a Madrid, sino que se reencuentran y las prolongan. Además, el que tejan relaciones entre sí no implica, en realidad, que dichas relaciones estén ausentes de conflictos. Al mismo tiempo, el hecho de que los y las jóvenes de dicho país de origen compartan las horas de recreo, como algunos profesores señalan, no significa que los contactos se prolonguen después de las clases ni tampoco al dejar definitivamente el Aula de Enlace.

\section{Culturas, mujeres y atuendos}

Como acabo de argumentar, los profesores relacionan la cultura con la forma de agrupamiento entre los pares, pero lo hacen también respecto de la ropa que utilizan sus alumnas, que es una manera de definir el tipo de feminidad de estas mujeres. A lo largo de este epígrafe me voy a detener a analizar este aspecto ${ }^{11}$.

La siguiente cita muestra cómo un profesor relaciona a las mujeres de origen latinoamericano con una vestimenta que califica de atrevida.
Marcelo: Dentro del instituto, ya te he dicho, aquí, la diversidad, ya te he dicho, introduce problemas, dificultades en el trabajo nuestro, porque eso es obvio. No es lo mismo tener población española que población extranjera porque desde problemas idiomáticos hasta de ciertas cosas culturales. Ejemplo, las chicas sudamericanas les gusta ceñirse y mostrarse. Y, ¿por qué? Pues yo no lo sé, pues porque, bueno es un rasgo que en sus países de origen, pues tal, y algunas tienes que decirle ipero hija mía tápate un poquito, por favor, que nos lo vas enseñando todo! (Entrevista a Marcelo. Profesor en el IES Cantueña. Junio de 2009).

Marcelo considera que el trabajo con alumnos extranjeros conlleva "dificultades" diferentes a las que supone la labor con los estudiantes autóctonos. Relaciona dichas dificultades con el desconocimiento del castellano, pero también con "cosas culturales". A la hora de explicar estas "cosas culturales" se refiere a la forma en la que las chicas procedentes de Sudamérica van vestidas. Unos modos que aglutina, deslegitima y caracteriza como indecorosos, ya que exhiben partes de sus cuerpos y emplean prendas que ajustan y marcan sus formas. Al mismo tiempo que generaliza dichos estilos a todas las chicas sudamericanas (una cuestión ya de por sí relevante), resulta todavía más significativo cómo los relaciona como propios o característicos de mujeres de estas procedencias. Unos modos, que desde su posición de profesor (y hombre) ve la necesidad de corregir, al menos, en el instituto. Una rectificación de la que se deriva que el estar en la escuela precisa de unas maneras apropiadas y correctas a la hora de comportarse, entre las que se incluyen la ropa que utilizar y el modo de usarla. Estos son, a mi modo de ver, algunos de los aspectos con los que se va construyendo un ideal de "buena estudiante".

Sin embargo, sus palabras no solo señalan los modos de vestir adecuados o pertinentes, sino también otros elementos. Marcelo, para explicar las dificultades de la diversidad en la escuela (a la que, por otro lado, relaciona directamente con la presencia de alumnado migrante), recurre a las diferencias culturales que considera que se manifiestan en los cuerpos de las mujeres y en sus maneras de cubrirlos/descubrirlos. Es decir, sus palabras no solo resultan pertinentes porque aglutinen, esencialicen y utilicen la tríada "diversidad-migración-problema", 
sino porque emplea los cuerpos de las chicas y sus modos de ataviarse para explicar las "dificultades" que la "diversidad" entraña en la escuela.

Frente a la mirada de Marcelo sobre las mujeres sudamericanas utilizo la visión de Juan, profesor del IES Cantueña, respecto de la "cultura árabe", a la que define como fácil de penetrar hasta un determinado punto. El punto en el que la posibilidad de "penetrar" se cierra, según Juan, es el trabajo sobre la "igualdad" de las mujeres. Un asunto que define como un "disparate", como un acto fuera de la razón.

-Juan: ...La cultura árabe puedes penetrar, pero a la hora de trabajar con las mujeres, igualdad con las chicas, es otro disparate, eso es otro disparate. Las chicas lo pasan fatal, eso es mucho disparate -Pilar: ¿Lo pasan fatal en las escuelas? -Juan: No, no, lo pasan fatal porque desde las casas les obligan a unas cosas y ellas se dan cuenta de que la vida es otra cosa. A ti te obliga tu padre a llevar velo con doce, con trece, con quince y tú qué vas a llevar velo si llevas aquí viviendo desde que tenías seis años, tú estás acostumbrada a esta cultura 12 .

(Entrevista a Juan. Equipo de Orientación del IES Cantueña. Junio de 2009).

De nuevo, aparece en el discurso de un docente una prenda de vestir (con connotaciones variadas como el hijab) empleada por las mujeres para explicar las "dificultades" del trabajo educativo con jóvenes que proceden de países con mayoría musulmana.

Sin querer penetrar en las constantes discusiones sobre el uso del hijab, he considerado fundamental hacer dialogar las palabras de Marcelo con las de Juan, ya que ambas sitúan en dos polos, aparentemente opuestos pero a su vez complementarios, las representaciones sobre la presencia de la diversidad cultural en las escuelas y el uso que hacen de los atuendos, cuerpos e "igualdad" de las mujeres para explicar las "problemáticas" de su día a día en los centros educativos ante la apertura a la "diversidad".

\section{Consideraciones finales}

Considero que en la escuela se da un proceso constante de culturalización, es decir, determinadas cuestiones sociales, económicas o propiamente escolares (y estas en interrelación con las dos anteriores) son reducidas a dificultades y soluciones étnico-nacionales (Nieto, 2003). Con ello se genera la alterización de determinados grupos sociales, como el caso descrito de los jóvenes procedentes de China, aunque dicho proceso no solo les afecta a estos, como he mostrado.

Por medio del mencionado proceso de culturalización la responsabilidad del desarrollo de los procesos de enseñanza y aprendizaje recae en el propio individuo (es decir, en su "carácter") y en los rasgos que se consideran característicos de cada grupo étnico-nacional, sin tener del todo en cuenta el papel que las propias acciones de la sociedad receptora (Nieto, 2003), el sistema educativo y los agentes escolares (profesorado, alumnado y familias) juegan en ella.

El sujeto es identificado (y sus diferencias son anuladas) con determinadas distinciones o rasgos, y estos rasgos son vistos como característicos de todos los miembros de un mismo grupo étnico-nacional (García García, 2002). Como señala Adela Franzé (2008), dicha identificación petrifica tanto a los sujetos como a los países de origen, invisibilizando las diferentes y múltiples relaciones en las que la subjetividad-en-proceso se conforma, así como la complejidad de los procesos históricos, sociales, económicos y políticos de dichos países de origen.

En este sentido, algunos jóvenes me han explicado cuestiones de carácter político, económico, social e histórico de sus lugares de nacimiento, que mi modo de ver, implican un fuerte potencial a la hora de comprender y profundizar en los discursos y debates referidos a las diferencias culturales en las propias clases, y también a la hora de indagar el papel de las relaciones coloniales en el desarrollo de determinados rasgos a los que se alude constantemente ${ }^{13}$.

Respecto de las relaciones coloniales, los docentes suelen limitarse a señalar situaciones de discriminación o de violación de los derechos humanos que se producen en otros países, invisibilizando las que tienen lugar en nuestros contextos más cercanos. Dicha invisibilización, a mi modo de ver, impide enfrentar y actuar directamente frente a las desigualdades que se generan en las escuelas, como explica con clarividencia Mica Pollock (2004) respecto de Estados Unidos. Al mismo tiempo genera un proceso de "otrización", cuyas consecuencias son definir al "otro" en términos de déficit y pensarse a sí mismo como exento de los 
males que a los otros se les atribuyen, lo que, por otra parte, acaba reforzando la percepción desigual y en definitiva una perspectiva colonial construida y argumentada a partir de las diferencias (que son percibidas como deficiencias) culturales.

En relación con las trayectorias escolares de los estudiantes de las Aulas de Enlace una vez abandonan el programa querría señalar que las diferencias culturales son utilizadas como un modo de justificación de unos itinerarios caracterizados por la desigualdad, ya que en pocas ocasiones continúan en las aulas ordinarias que corresponden a los estudiantes por edad, y los jóvenes suelen ser orientados por los equipos pedagógicos hacia otros grupos o programas que trabajan fuera de los grupos de referencia (Cucalón y Del Olmo, 2010). De tal modo que un mismo estudiante inmigrante/extranjero puede desarrollar su escolarización en diversos dispositivos que se encuentran en los límites del sistema educativo, lo que, por otra parte y fundamentalmente, puede tener repercusiones en el acceso a un mercado laboral altamente segmentario y segmentado (Ávila y Malo, 2007; Jociles et al., 2012).

Como ha podido verse en este texto, los discursos en torno a las diferencias culturales van desde el respeto hacia las mismas, aunque impliquen también un proceso de esencialización, a considerarlas problemáticas en los espacios educativos y necesarias de corregir. Sin embargo, a la hora de explicar las trayectorias de los jóvenes inmigrantes/extranjeros, los docentes entrevistados no solo hacen referencia a la cultura, aunque esta se haga especialmente significativa teniendo en cuenta las características y finalidades de las Aulas de Enlace, sino también a otros aspectos referidos al origen de los jóvenes. En este sentido, también mencionan el sistema educativo de referencia, las familias y la lengua materna. Por temas de espacio no he podido referirme a estos tres aspectos, pero me gustaría al menos señalarlos para no simplificar el discurso de los docentes.

Para finalizar querría indicar que la argumentación mantenida en este artículo, según la lectura que de él que se haga, podría llevar a una culpabilización de los profesores respecto de la situación de los estudiantes inmigrantes/extranjeros. Sin embargo, sus discursos deben entenderse en el contexto de un sistema educativo compuesto, además de por los propios profesores, por las administraciones, las normativas, las editoriales, la formación docente y las familias, entre otros agentes. De tal modo que no actúan como actores aislados, sino en respuesta ante fuertes presiones e imaginarios a partir de los cuales cada uno/a intenta desarrollar lo que considera su función docente. Una función que, gracias al trabajo de campo etnográfico, he podido ver que va mucho más allá de los discursos y plantea otras prácticas igualmente significativas, como las relaciones de confianza entre profesores y estudiantes que se prolongan fuera del horario escolar y los cuidados y el acompañamiento que hacen a los estudiantes tanto en cuestiones académicas como personales. Observar y entender todos estos aspectos es lo que me permite dar cuenta de la complejidad del día a día en las escuelas y, concretamente, en las Aulas de Enlace.

\section{Referencias Citadas}

Ávila, D. y Malo, M.

2007 ¿Quién puede habitar la ciudad? Fronteras, gobierno y transnacionalidad. En Madrid: ¿la suma de todos? Globalización, territorio y desigualdad, editado por Observatorio Metropolitano, pp. 505-534. Editorial Traficantes de Sueños, Madrid, España.

Cucalón, P.

2015 Tránsitos, límites y migrantes en las escuelas. Una investigación en las Aulas de Enlace de la Comunidad de Madrid. Editorial Universidad Complutense, Madrid, España. Cucalón, P. y Del Olmo, M.

2010 Redefiniendo trayectorias escolares. Las aulas de enlace en la Comunidad de Madrid. Revista de la Asociación de Sociología de la Educación, Vol. 3, № 2: 223-233.

Del Olmo, M.

2010 Re-Shaping Kids Through Public Policy on Diversity. Lessons from Madrid. Editorial Navreme Publications. Vol. 11, Madrid/Vienna.
Fassin, D.

2006 Nommer, interpréter. Le sens commun de la question raciale. En De la question sociale à la question raciale? Représenter la société française, editado por D. Fassin D. y Fassin E., pp. 9-36. Editorial La découverte, Paris, Francia. Franzé, A.

2008 Discurso experto, educación intercultural y patrimonialización de la "cultura de origen”. En ¿Es la escuela el problema? Perspectivas socio-antropológicas de Etnografía y Educación, editado por A. Franzé y M. Jociles, pp. 61-89. Editorial Trotta, Madrid, España.

García Canclini, N.

2006 Diferentes, desiguales y desconectados. Mapas de la Interculturalidad. Editorial Gedisa, Barcelona, España.

García García, J. L.

2007 Cultura. En Diccionario de Relaciones Interculturales. Editado por A. Barañano, J.L. García, M. Cátedra y M.J. 
Devillard, pp. 175-178. Editorial Universidad Complutense de Madrid, Madrid, España.

García Castaño, J.; Granados, A.; Pulido, R.

1999 Reflexiones en diversos ámbitos de construcción de la diferencia. En Lecturas para educación intercultural, editado por J. García Castaño y A. Granados, pp. 15-46. Editorial Trotta, Madrid, España.

Jociles, M.; Franzé, A.; Poveda, D.

2012 La diversidad cultural como problema: representaciones y prácticas escolares con adolescentes de origen latinoamericano (Madrid). Alteridades, 22 (43): 63-78.
Ministerio de Educación, Cultura y Deporte.

2014 Datos y cifras. Curso escolar 2014-15. Editorial Ministerio de Educación, Cultura y Deporte, Madrid, España.

Nieto, G.

2003 La inmigración China en España Definiciones y actuaciones en integración social. Cidob d'Affers Internacionals, 63: $167-189$.

Pollock M.

2004 Color mute: Race Talk Dilemas in an American School. Editorial Princeton University Press, New Jersey, USA.

Notas

1 En el Estado español durante el curso 2013-14 había un total de 731.167 estudiantes que no poseían la nacionalidad española en las Enseñanzas de Régimen General no universitarias y de Régimen Especial. Esta cifra es un 4,2\% inferior a la que se dio en el 2012-13 y un 6,4\% a la de 2010-11, que es la más alta desde el año 2000 con un total de 781.141. Estas cifras muestran un importante descenso en los últimos años, pero a su vez contrastan con los 207.112 estudiantes extranjeros que había en el 2001-02. Respecto de la Comunidad de Madrid, que es la región de la que se ocupa el presente artículo, es preciso señalar que en el curso 201314 el alumnado no universitario sin nacionalidad española suponía el 11,6\% del total, siendo una de las regiones del país con el porcentaje más elevado. Ver en Datos y Cifras. Curso escolar 2014-15. Consultada en http://www.mecd. gob.es/servicios-al-ciudadano-mecd/estadisticas/educacion/ no-universitaria/alumnado/matriculado/2013-2014--DatosAvances.html, el 19 de abril de 2015.

2 El grupo de referencia es aquel en el que el alumno o alumna del Aula de Enlace se tiene que incorporar cuando acaba el programa. Mientras están en el Aula de Enlace dicho grupo lo determina la edad, pero una vez terminan lo que lo marca ya no es la edad, sino la decisión tomada por el equipo docente en función de los conocimientos académicos, la destreza con el idioma u otras razones, como las características de los profesores de las clases ordinarias (Del Olmo, 2010).

3 En España existe una modalidad de centro escolar llamado privado-concertado, que se caracteriza por recibir financiación pública para el mantenimiento de la escuela y el pago del salario de los profesores, pero la gestión del colegio corre a cargo de una entidad privada como una empresa, una organización religiosa o una cooperativa de docentes.

4 Todo ello con la finalidad de respetar su anonimato.

5 En este texto me voy a centrar en los discursos de los docentes, para el análisis de las imágenes de los alumnos remito a Cucalón (2015).

$6 \quad$ El alumno mentor era un programa que pusieron en marcha algunas escuelas con la finalidad de que un estudiante del centro ayude y acompañe a un recién llegado del extranjero en las primeras semanas de su escolarización. En el caso del IES Cantueña los alumnos mentores solían ser antiguos estudiantes del Aula de Enlace.

8 Una dificultad que, por otro lado, está estrechamente relacionada con uno de los objetivos de las Aulas de Enlace: facilitar la incorporación y acortar el periodo de integración de este alumnado al sistema educativo español.

9 Se refiere a otro grupo del $1^{\circ}$ de la E.S.O (Educación Secundaria Obligatoria).

10 En España se califica de 0 a 10, siendo el 10 la nota máxima, de manera que el 9 al que se refiere este profesor es una excelente calificación.

11 En mi trabajo de campo las referencias a la ropa del alumnado inmigrante/extranjero se han dado exclusivamente en relación con las chicas. Por ello, que no haya hecho ninguna alusión en este artículo a las prendas de los chicos.

12 Por medio de mis interpretaciones no querría silenciar determinadas situaciones que los y las profesoras narran sobre la exigencia que algunos padres pueden ejercer sobre sus hijas a la hora de obligarlas a llevar hijab cuando las mujeres no lo desean. No son situaciones que haya podido presenciar, sino experiencias que los profesores me han explicado. Aunque en mi trabajo de campo en el IES Cantueña y el Colegio Mica no he trabajado directamente con alumnas de esta religión, sí pude entrevistar a Naima. Esta joven asistió a un Aula de Enlace, junto con su hermana, en un Instituto de Enseñanza Secundaria del Distrito de Villaverde (en la ciudad de Madrid). La entrevista desarrollada no solo me permitió conocerla, sino pensar y asistir a la contestación por parte de una chica de tan solo catorce años a los estereotipos en torno a Marruecos y a familias como la suya. Este es un caso aislado y no representativo de todo un colectivo, pero me permitió cuestionar las percepciones del profesorado sobre la "cultura árabe".

13 En relación con esto, García Canclini señala que si las diferencias culturales pierden su entidad sociohistórica, dejan de ser vistas como rasgos formados en etapas donde la desigualdad operó de maneras distintas, y por tanto susceptibles de cambiar en procesos futuros. Quienes suponen que en las diferencias culturales está su mayor fortaleza, tienden a absolutizarlas (García Canclini, 2006: 47). 